\title{
Uma comparação do baixo crescimento econômico brasileiro em relação aos países do BRICS ${ }^{1}$
}

A comparison of low economic growth in Brazil towards BRICS countries

\section{Luiz Carlos Ribeiro Neduziak ${ }^{2}$}

\section{RESUMO}

A economia brasileira vem apresentando recentemente um comportamento destoante em relação ao crescimento do PIB dos países componentes do BRICS (Brasil, Rússia, Índia, China e África do Sul). o presente ensaio busca assinalar algumas das possíveis causas desse baixo crescimento.

Palavras-chave: BRICS; Crescimento Econômico; Economia Contemporânea.

\section{ABSTRACT}

The recent Brazilian economy has been presenting a discordant behavior towards GDP growth of BRICS countries (Brazil, Russia, India, China and South Africa). This essay seeks to identify some of the possible causes of this low growth.

Keywords: BRICS; Economic Growth; Contemporary Economics.

A sigla BRICS tem origem na obra Building Better Global Economic BRICs de Jim O'Neill (2001), referindo-se a um grupo de países que teriam um crescente papel nas dinâmicas da economia global no século XXI. Esses países seriam: Brasil, Rússia, Índia, China e, desde 14 de abril de 2011, conta com a África do Sul3 ${ }^{3}$. Presente em diversos estudos das relações internacionais contemporâneas, a sigla BRICS colocou seus

\footnotetext{
${ }^{1}$ Artigo recebido em 03 de junho de 2013 e aprovado para publicação em 10 de outubro de 2013.

${ }^{2}$ Economista, doutorando pelo Programa de Pós-Graduação em Desenvolvimento Econômico (PPGDE) da Universidade Federal do Paraná (UFPR), Curitiba, Brasil.

${ }^{3}$ Disponível em: http://www.bloomberg.com/news/2011-04-12/brics-gain-global-influence-as-southafrica-joins-russia-s-medvedev-says.html. Acesso em 02 de junho de 2013.
} 
membros em constante acompanhamento por diversos atores internacionais que os reconhecem como economias em processos de expansão e crescimento. Para além do G8 - grupo das economias desenvolvidas, composto por Estados Unidos, Japão, Alemanha, Reino Unido, França, Itália e o Canadá (antigo G7), mais a Rússia - o BRICS é formado por Estados em desenvolvimento cujas economias mostram-se aquecidas e em expansão, ocupando um espaço intermediário entre Estados desenvolvidos e os em desenvolvimento.

Brasil, Rússia, Índia, China e a África do Sul estariam todos em um relativo estágio de proximidade econômica e de atuação no mercado internacional, sendo classificados como "mercados emergentes" - devido aos índices e velocidade de seus desenvolvimentos econômicos nas últimas décadas ${ }^{4}$. A relevância internacional do grupo, ainda que haja movimentações geopolíticas em seus interesses ${ }^{5}$, pode ser analisada majoritariamente pela perspectiva econômica e as comparações de desenvolvimento entre os membros tornam-se constantes. Desde 2009, os líderes do grupo realizam cúpulas anuais onde tratam de política, economia, mercado internacional e demais dinâmicas financeiras, almejando um melhor desenvolvimento de seus membros.

No caso do Brasil, a economia vem experimentando, em sua conjuntura mais recente, uma incongruente realidade macroeconômica representada pelo crescimento econômico em arrefecimento, associado a um processo inflacionário difuso e sistêmico. Quando se leva em consideração os postulados da teoria econômica, os quais assinalam uma relação inversa entre taxa de juros - crescimento econômico, taxa de juros inflação e direta entre crescimento do PIB - inflação (isto é, quanto maior a taxa de juros, menor o crescimento econômico e a inflação e quanto menor o crescimento do PIB, menor a inflação), percebe-se o dilema em que se encontra o Brasil.

\footnotetext{
4 "O Banco Mundial define emergente aquela economia cujo nível de geração de riqueza, medida pelo produto nacional bruto (gross national product) per capita, encontra-se abaixo daquele de economias desenvolvidas". Disponível em: http://www2.dbd.pucrio.br/pergamum/tesesabertas/0310792 06 cap 05.pdf. Acesso em 02 de junho de 2013.

5 Disponível em: http://www.reuters.com/article/2008/06/08/us-russia-forum-bricidUSL071126420080608? pageNumber=2\&virtualBrandChannel=0. Acesso em 02 de junho de 2013.
} 
Faz quatorze anos que nossas autoridades monetárias adotaram o Regime de Metas de Inflação como âncora das expectativas de preços domésticos, ademais da busca de superávits primários pelo governo e um regime de câmbio flutuante. Essas três características encerram o tripé da política econômica que esperavam nossas autoridades políticas e econômicas direcionar a economia para o desenvolvimento econômico sustentado, não obstante, em prática, verifica-se o contrário: um crescimento econômico baixo e volátil. Se comparado o Brasil aos países do BRICS (Brasil, Rússia, Índia, China e África do Sul), percebe-se que a economia nacional não se alinha à evolução do produto bruto dessas economias, conforme assinala o Gráfico 1, abaixo:

\section{Gráfico 1 - Taxa de crescimento real do PIB no período de 2004 a 2011.}

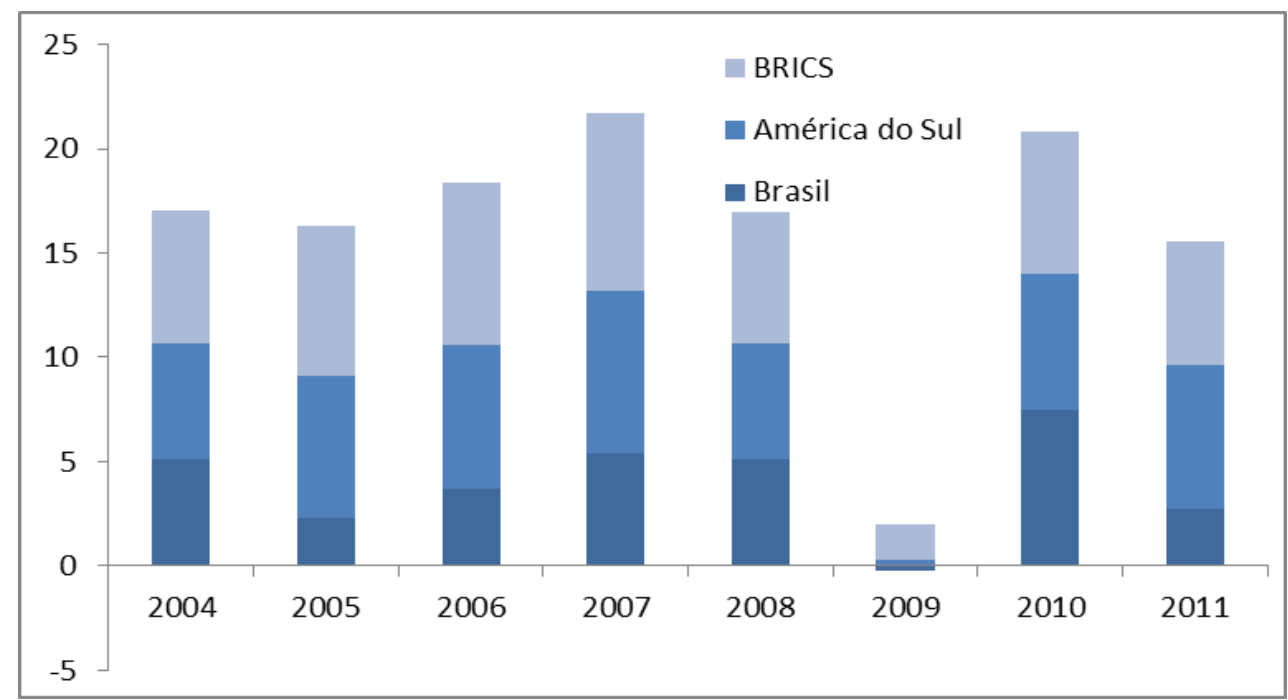

Fonte: elaboração própria do autor, 2013.

Pode-se depreender uma taxa de crescimento sistematicamente inferior a dos demais países do "bloco", no período de 2004 a 2011, à exceção do ano de 2010, mesmo se levar em conta o ciclo de redução de juros iniciado no ano de 2010. É lugar comum, nas academias e meios de comunicação brasileiros, atribuir o baixo crescimento econômico à atuação restritiva da Política Monetária adotada pelo Banco Central (isto é, 
a manutenção da taxa básica de juros - SELIC - em níveis elevados). Se os juros básicos fossem a principal causa do baixo crescimento nacional, as reduções recentes dos juros já teriam surtido efeito sobre a economia.

Desse modo, pergunta-se: quais as principais causas do baixo crescimento brasileiro em relação aos países do BRICS? A resposta deve ser buscada na estrutura da Política Econômica de longo prazo, que se refere ao aumento no investimento público e privado e inovação tecnológica, à desoneração do arcabouço tributário e a redução de custos operacionais e logísticos de nossa infraestrutura econômica. Desse modo, possivelmente, poderemos nos equiparar, pelo menos do ponto de vista econômico, à evolução daquela variável econômica nos países representativos do Sul.

Assim, de forma comparativa com os demais membros do grupo, o Brasil possui desafios econômicos, sobretudo nas áreas de inovação tecnológica, tributária e infraestrutura de exportação - tanto a física como as institucionais. No caso da Rússia, China, Índia e África do Sul, outras variáveis contribuem para o crescimento acentuado em relação ao Brasil. Todavia, não percebe-se uma ausência total de dificuldades em suas economias. Portanto, em uma breve análise comparativa - entre economias emergentes de proximidades relativas - o Brasil possuiria um baixo crescimento comparativo por manter uma estrutura política econômica pouco eficiente diante das dinâmicas mais competitivas internacionais: com baixa tributação; menor custo na logística de exportação; e maior inovação tecnológica às necessidades de mercado do século XXI.

\section{Referências Bibliográficas}

MINISTÉRIO DAS RELAÇÕES EXTERIORES. BRICS: Brasil, Rússia, Índia, China e África do Sul. Disponível em: http://www.itamaraty.gov.br/temas/mecanismos-interregionais/agrupamento-brics. Acesso em 02 de junho de 2013.

O'NEILL, Jim. Building Better Global Economic BRICs. Goldman Sachs, nov. 2001. Disponível em: http://www.goldmansachs.com/our-thinking/archive/buildingbetter.html. Acesso em 02 de junho de 2013. 